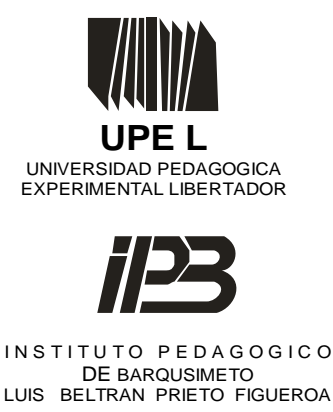

DE BARQUSIMETO
LUIS BELTRAN PRIETO FIGUEROA

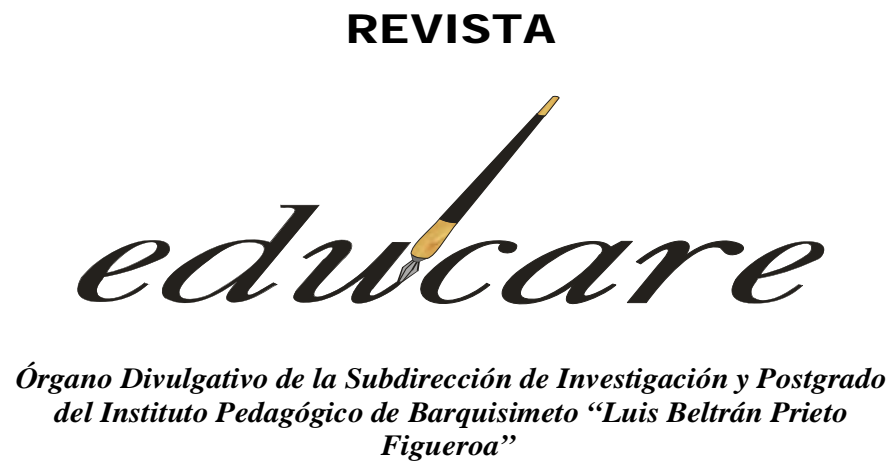

Figueroa"

BARQUISIMETO - EDO. LARA - VENEZUELA

NUEVA ETAPA

FORMATO ELECTRÓNICO

DEPOSITO LEGAL: ppi201002LA3674

Volumen $18 \mathrm{~N}^{\circ} 1$

ISSN: 2244-7296

Enero - Abril 2014

\title{
LA ÉTICA COMPLEJA DE MORÍN EN EL CONTEXTO EDUCATIVO
}

COMPLEX ETHICS OF MORIN IN THE EDUCATIONAL CONTEXT

\author{
Beatriz E. Terán T.* \\ Lesdy M. Piña M. **
}

*UNIVERSIDAD PEDAGÓGICA EXPERIMENTAL LIBERTADOR
**UNIVERSIDAD POLITĖCNICA TERRITORIAL ANDRÈS ELOY BLANCO 


\section{LA ÉTICA COMPLEJA DE MORÍN EN EL CONTEXTO EDUCATIVO COMPLEX ETHICS OF MORIN IN THE EDUCATIONAL CONTEXT}

ENSAYO

Recibido:04-09-13
Beatriz E. Terán T. ${ }^{*}$

UCLA

Lesdy M. Piña M. **

UPTAEB

Aceptado: 18-02-14

\section{RESUMEN}

Este ensayo es producto de una investigación documental enmarcada en el paradigma cualitativo donde pretendemos plantear algunas reflexiones sobre la ética compleja de Morín en el contexto educativo. Utilizamos la metodología hermenéutica. Analizamos e interpretamos bajo nuestra perspectiva subjetiva los diferentes elementos de la ética compleja en el contexto educativo. Finalmente, concluimos que la ética compleja también llamada de resistencia y de religación; es indispensable en la educación porque permite al hombre alejarse de la noción del mal elevando su dimensión altruista. Esta última, necesaria durante la formación educativa de todo ser humano, debido al acompañamiento que recibe de otros seres semejantes a él con los que debe compartir sus conocimientos, habilidades y valores como parte del orden social y planetario.

Descriptores: Ètica compleja de religación o de resistencia, noción del mal y el bien, educación

\begin{abstract}
This paper is a product of a documental research based on the qualitative paradigm. We pretend to establish some reflections about the Morín's complex ethics in the educational context. We used the hermeneutic methodology. We analyzed and interpreted under our personal perspectives the different elements of the complex ethics in the educational context. Finally, we conclude that the complex ethics, also called ethics of fraternity and ethics of resistance; is an essential aspect of education because it allows human being to move away from the evil notion, elevating his altruistic dimension. The latter, necessary during any educational formation, especially if we take into account that human beings are never alone and always share knowledge, skills and values with other people as part of a social and planetary order.
\end{abstract}

Keywords: complex ethics, ethics of fraternity, ethics of resistance, good and evil notions, education.

\footnotetext{
* Magíster en Enseñanza del Inglés como Lengua Extranjera (UPEL-IPB-2004), Profesora de Inglés (UPELIPB-2000), TSU en Turismo- (IUTAJS-1993). Lugar de trabajo: UCLA-DCyT. Correo: beatriz_et@hotmail.com

** Magíster en Educación en Enseñanza del Inglés como Lengua Extranjera (UPEL-IPB-2005), Profesora de Inglés (UPEL-IPB-2000), Lugar de trabajo: UPTAEB. Correo: lesdymagdalena@hotmail.com
} 


\section{INTRODUCCIÓN}

El planeta Tierra, nuestro mundo, es un "grano de polvo cósmico donde ha emergido la vida” (Morín, 1993, p.46). Un espacio complejo con una inmensa diversidad de seres vivos desde microorganismos, plantas, animales, además de recursos naturales que conforman la biósfera. Un lugar con una gran diversidad de formas, espacios, colores, sustancias, elementos, energías y situaciones que se cruzan y se mezclan para formar un mundo de infinita pluralidad.

Como parte de esa variedad de especies vivientes originadas en el planeta, estamos nosotros los seres humanos. Somos parte de un todo inevitablemente relacionado. Lo que hacemos y la forma como actuamos ejerce alguna influencia en algo más, sin que lo podamos evitar. Nuestro poder de raciocinio nos ubica, no en una escala superior en relación con otros seres, sino en un puesto de gran responsabilidad y compromiso sobre la vida de la tierra, su biósfera, y todo lo que existe; entendiendo la fragilidad y mortalidad de todo y de todos.

Cada ser humano es una "unidad/diversidad compleja” (Morín, ob. cit, p.118), lo cual implica la necesidad de comprender que somos diferentes pero a la vez formamos parte de una misma entidad. Nuestras particularidades diversas, mezcladas y complementadas con las de nuestros acompañantes planetarios constituyen la complejidad que nos caracteriza.

La diversidad de la cual formamos parte, nos obliga a un renacer del ser humano. Esto es, un hombre menos individualizado y más capaz de acercarse a la sociedad. Un sujeto apto para conformar una comunidad planetaria de individuos que conlleve a una nueva concepción de desarrollo, concerniente específicamente con lo humano.

Más que relacionar el desarrollo humano con cuestiones biológicas o económicas como suele hacerse, nos referimos a un desarrollo comunitario, social que acerque un hombre a otro, que una y no separe a pesar de las diferencias propias de cada individualidad. Tal desarrollo de humanidad sólo puede lograrse por medio de la superación del odio, la incomprensión y la mentira, entre otras situaciones negativas, que mayormente emergen del mismo hombre y lo separan de los demás seres que lo rodean. 
Si bien es cierto que lo negativo, lo separador y en definitiva, el mal provienen no sólo del interior del ser humano sino también de su exterior; el hombre se ve en la obligación de luchar a cada instante de su vida contra esa negatividad. Es así como el amor, la solidaridad, la comprensión, la compasión y la religación nos permiten no sólo resistir al mal, sino también unir aquello que está separado. Para ello, debemos reconocer que el hombre está conformado por una dialógica egocéntrica/altruista, es decir, que existe en el ser humano, lo que Morín (2006) señala como “el carácter vital del egocentrismo así como la potencialidad fundamental del desarrollo del altruismo”. (p.26)

Esa dualidad egocentrista/altruista, inseparable y complementaria, supone comprender que el hombre se aleja de sus pares mediante el egoísmo propio del egocentrismo; pero a la vez se acerca a sus pares a través de su modo del ser filantrópico, desprendido y en definitiva humanitario. La dimensión egocéntrica lo lleva a que sólo piense en él y todo lo que haga se fundamente en su propio beneficio y satisfacción personal. La dimensión altruista, por su parte, lo invita a que considere y comprenda a la humanidad. Así, notamos la importancia que tiene alimentar nuestra dimensión altruista y evitar que la egocéntrica se haga mayor y nos conduzca a un desgaste de fundamentos colectivos, que en suma llevan a situaciones críticas tanto individuales como sociales.

Es evidente que cualquier circunstancia que rodee al hombre incide en mayor o menor grado no sólo en él, sino también en otros seres que lo acompañan. Inevitablemente somos seres duales conformados por una fuente individual, a través de la cual asumimos nuestro sentido de responsabilidad ante el mundo; y una fuente social, localizada en las normas que nos inducen a un actuar solidario con el resto de los individuos. Sin embargo, al tratar de separarnos de la sociedad incurrimos en un conflicto que Morín (ob. cit) señala como la crisis de "la religación individuo/especie/sociedad”(p.29); y que no es más que una crisis ética que debilita nuestras fuentes de responsabilidad y solidaridad.

Desde esta perspectiva, el mismo Morín (ob.cit) señala que no se requiere buscar nuevas fuentes para la ética, sino simplemente renovar las ya existentes. Así, la ética debe llevarnos a religar con nuestros pares, es decir, con toda la especie humana en general y en los diferentes contextos sociales. Tal religación, debería emerger “de la conciencia moral”, es decir, de la razón del hombre que le indica si está obrando bien o mal. Sin embargo, la religación ética también pudiera surgir de situaciones críticas como la pesadumbre, el vacío 
ético, entre otras; todas ellas provenientes del debilitamiento de las fuerzas que conducen a la unión, comprensión, compasión, amor, y en definitiva al bien.

Desafortunadamente, las fuerzas separadoras suelen ser más enérgicas que aquellas que unifican. Sin embargo, al tiempo que se actúa en favor de la dispersión y separación, también se actúa en la regeneración de la unión. La complejidad de nuestro pensamiento y de nuestro mundo, permite que ocurra transformación y auto-reorganización continua; y esa reorganización implica que a la vez exista una desorganización complementaria. De allí, que vivamos en una realidad donde cabe no sólo el orden, sino también el desorden como elementos integrados, en lugar de contradictorios. Así, podemos decir que nos encontramos en un universo con más complicidad que enemistad conformado por un “tejido de elementos heterogéneos inseparablemente asociados” (De Almeida 2008, p. 24).

Lo complejo de nuestro mundo, contempla que dentro del bien se encuentre el mal y viceversa, por lo tanto, nuestras fuerzas de unión o religación siempre estarán sometidas a las fuerzas separadoras del mal. La debilidad a la que están condenadas las fuerzas de unión y por ende, del bien, conlleva a una ética cuya premisa sea la resistencia al mal, es decir, la intransigencia ante todo lo separador.

La ética de religación conduce a resistir y enfrentar la crueldad del mundo y la crueldad humana que en definitiva llevan a situaciones separadoras. Así, lo que perseguimos por medio de la ética de religación tiene que ver principalmente con el hecho de reflejar que "el hombre no es sólo un montón de huesos y tejidos regidos por una serie de elementos” (Spear W. 1997, p.190). El ser humano es una unidad multidimensional con una gran complejidad, compuesto por elementos racionales, emocionales, físicos, biológicos, psíquicos, culturales, sociales e históricos integrados. De allí, que todas las actividades en las cuales el hombre se involucra, deben conllevar a mantener esa integración.

La educación como una de las actividades humanas más importantes y cruciales en la vida de todo hombre debe conducir a situaciones unificadoras que permitan la integración del ser humano con sus semejantes y con otros seres vivos. Sin embargo, en lugar de mantener esta unión, la educación más bien separa. Los docentes se vuelven incapaces de instruir sobre métodos que permitan establecer un conocimiento del mundo de manera global, y no sólo de sus partes. De esta forma, negamos el hecho de que la sociedad forma 
parte del individuo y viceversa; todo lo cual queda evidenciado a través del lenguaje, los saberes, los deberes y las reglas sociales.

Es necesario localizar en la educación a la condición humana, entendiendo que ambas son complejas (De Almeida, ob. cit), por lo que sus constituciones deben analizarse de forma entrelazada; y sus objetivos deben conducir siempre a la unión. Una actividad como la educación debe valerse de la ética desde una visón compleja para formar ciudadanos con una condición humana capaz de resistir situaciones que potencian la noción separadora del mal y aniquilan la noción unificadora del bien.

En función de esta hermeneusis de la ética compleja, de resistencia o de religación, pretendemos con esta investigación documental plantear algunas reflexiones sobre la ética compleja de Morín en el contexto educativo. La ubicación de este estudio en el paradigma cualitativo hace inevitable percibir la subjetividad de las investigadoras durante todo el informe investigativo. Así, utilizamos la metodología hermenéutica para analizar e interpretar las teorías referenciadas y asumir postura en relación con los aspectos planteados por Edgar Morín acerca de la ética y la educación.

\section{EXPOSICIÓN DEL TEMA}

Tratando de cumplir con nuestro propósito investigativo, nos preguntamos entonces, ¿seremos capaces de resistir nuestro propio egocentrismo, superarlo y ahondar en la dimensión altruista de nuestro ser que nos conduce a la religación con el prójimo?, ¿Cumple la educación con esa función fundamental de religación ética?. Nuestra experiencia como docentes nos permite expresar responsablemente, que la educación separa cada elemento que constituye de manera perfecta al individuo, en lugar de mantener la unión.

Enfrentar la educación del futuro implica entonces, que los docentes tratemos de enfocar el aprendizaje de conocimientos integrales y no divididos. De esta forma, para que el conocimiento sea pertinente, el individuo debería tomar en cuenta el contexto, lo global, lo multidimensional y lo complejo. Un conocimiento adquirido fuera de su contexto, pierde sentido. Por lo que es importante ubicar las informaciones en sus escenarios apropiados (Morín, 1999). 
En este mismo orden de ideas, los docentes debemos comenzar a dirigir nuestros objetivos hacia la realización de una labor que permita establecer un conocimiento integral del mundo y no sólo de sus partes; comprendiendo que los estudiantes son seres humanos complejos y multidimensionales constituidos por elementos entrelazados y de gran variedad. Así, requerimos de una unidad en la diversidad para establecer con firmeza que la variedad contenida en el mundo debe llevarnos a un conocimiento integral y unificador.

Ser capaces de visualizar y comprender esa unidad en la diversidad, representada en este ensayo por la figura 1, implica entender que a pesar de nuestras diferencias físicas, intelectuales, contextuales e incluso valorativas, todos somos parte de una misma realidad. Ese hecho inevitable no solamente nos une, sino que además nos permite ver diferentes matices y perspectivas de esa realidad que vivimos.

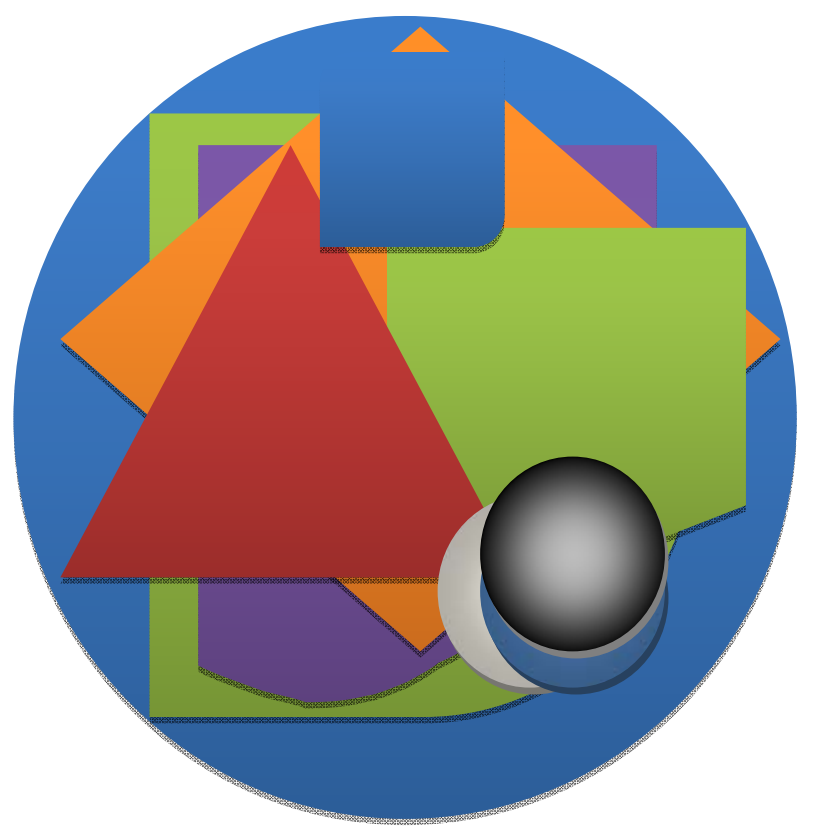

Gráfico 1. Unidad en la Diversidad.

Estando conscientes de lo que sucede en el mundo, seremos capaces de no aislarnos y alejarnos de los fenómenos planetarios que ocurren día a día. En este sentido, es necesario que la educación incluya un tipo de conocimiento global, integral y planetario que nos permita reconocer en primer lugar, nuestra diversidad y en segundo lugar, lo terrenal de nuestra identidad; y así sentirnos identificados con el resto del mundo que nos rodea. La educación plateada bajo la ética compleja debe llevarnos a comprender y estar conscientes 
de que todos los seres humanos pertenecemos al mismo planeta sin importar los antagonismos que puedan existir relacionados con religión, política, economía y cultura, entre otras circunstancias.

La ética compleja nos invita a evitar la crueldad, la barbarie, la intolerancia, la falta de misericordia y de humildad; y a partir de ello, poder "reducir la crueldad humana" a través de la exaltación de la consciencia. En tal sentido, la ética compleja se basa en la dualidad complementaria de razón/pasión evitando situaciones subjetivas del ser humano que provocan descontroles y excesos. La ética compleja trabaja en pro de "las fuerzas débiles de la religación", es decir, su esfuerzo se radica en elevar los niveles de colaboración, entendimiento, amor, tolerancia y conciencia que existen dentro del ser humano, por lo que el rol de la educación en la religación ética es crucial (Morín, ob. cit, p. 25).

Nos referimos propiamente a un tipo de educación que con inteligencia y amor, le permita al hombre comprender varias situaciones: a) que dentro de él existe el bien y el mal; b) que en el mundo existe el bien y el mal; c) que el bien y el mal no son realmente antagónicos, sino que se complementan; y d) que el hombre es egocéntrico pero también altruista por lo que es capaz de procurar el bien para sí mismo, pero también para los demás.

La comprensión se convierte entonces en un saber imprescindible conducente al logro de la comunicación entre los seres humanos. Por esta razón, se hace necesario el estudio de la incomprensión desde sus raíces. Morín (ob. cit) plantea, que una finalidad de la educación para el futuro debe ser la comprensión entre los humanos. Para que las relaciones humanas no fracasen, se debe comprender sin esperar nada a cambio, hay que argumentar sin castigar, ser tolerantes ante situaciones que parezcan según nuestro criterio malas o adversas. Es pues así, como la comprensión entre las personas debe estar presente como un valor y tener siempre en cuenta que comprender, es también aprender y re aprender permanentemente.

El aprendizaje logrado por medio de una comprensión real, inevitablemente ayuda a la integración necesaria de los tres elementos que constituyen el género humano: individuo/sociedad/especie. Estos elementos son inseparables y coproductores el uno del otro y su unidad se produce a través de lo que Morín (ob. cit) llama la ética del género 
humano. En consecuencia, podemos decir que la educación debe llevar a una tipo de ética que contemple el carácter trino del ser humano y construya democracia y ciudadanía terrestre. Al mismo tiempo, la educación debe asumir a la humanidad como comunidad planetaria y a la escuela como un laboratorio de vida democrática, donde la clase sea un lugar de aprendizaje a través del debate, de la toma de conciencia de las necesidades, y la comprensión del pensamiento de los demás.

Por otra parte, al tiempo que tratamos de comprender y ser comprendidos podemos cometer errores. Lo cambiante y frágil del conocimiento humano y nuestro empreño en alcanzar la certeza de lo que nos rodea puede llevarnos a errar. Sin embrago, a través de aquello que conocemos como educación podemos lograr el equilibrio necesario para socavar nuestros desaciertos y desafiar más racionalmente las incertidumbres.

La educación debe permitirnos aprender a enfrentar las incertidumbres, esperar lo inesperado, y tener la inteligencia suficiente para tratar de no predecir nuestro futuro, ya que en un mundo tan cambiante, el progreso de la humanidad es impredecible. Es así como los seres humanos debemos ser racionales y autocríticos para poder saber interpretar nuestra realidad, manteniendo siempre el alerta sobre el riesgo y la precaución, afrontando la incertidumbre con plena conciencia. En este sentido, Morín (ob. cit) plantea a la ética como uno de los saberes necesarios para enfrentar la educación del futuro y todo lo que ésta envuelve.

\section{APLICACIÓN PRÁCTICA}

¿Cómo aplicar la ética compleja en la educación? Al tratar de responder esta cuestión, encontramos suficientes elementos importantes que nos conducen no sólo a establecer una relación necesaria, profunda y muy fuerte entre la educación y la ética, sino también a plantear de manera práctica la aplicación de ésta última en la actividad educativa.

Cada vez que el docente se comunica con sus estudiantes, establece una conexión que involucra un aprendizaje no sólo de conocimientos que obviamente se transmiten de forma consciente y planificada, sino también una serie de valores que mayormente se transmiten de manera inconsciente e inevitable. Así, las expresiones y conductas utilizadas por el docente son inmediatamente captadas por los estudiantes y aprendidas mediante el ejemplo. 
La escuela no sólo representa el lugar donde acudimos a formarnos intelectualmente, sino que es básicamente un espacio de socialización, de allí que "en la escuela se convive en la misma medida que se aprende” (Boggino 2004, p.29). En la escuela compartimos saberes, valores, sentimientos, creencias, alegrías, penas, en fin, compartimos nuestro tiempo y espacio con otros seres muy parecidos o muy distintos a nosotros, pero absolutamente necesarios para nuestras vidas.

Cada ser humano es un Principito habitando "un planeta apenas más grande que él” y con la gran "necesidad de un amigo" (De Saint Exupéry, 2010, p.. 16). En este sentido, la escuela debe tratar de proveer a sus estudiantes de las formas más efectivas de socialización y unión de humanos con humanos apoyando la práctica pedagógica sobre las bases de "la ética y la tolerancia, el respeto y el cuidado mutuo” (Boggino, ob. cit, p.33).

¿Cuál puede ser la manera más práctica de realizar esta labor ético-pedagógica? Al respecto, las enseñanzas del Principito, resultan bastante útiles:

En el planeta del principito había, como en todos los planetas, hierbas buenas y hierbas malas...si se trata de mala hierba es preciso arrancarla inmediatamente en cuanto uno ha sabido reconocerla...si un baobab no se arranca a tiempo, no hay manera de desembarazarse de él más tarde; cubre todo el planeta y lo perfora con sus raíces (De Saint Exupéry, ob. cit, p. 18).

En tal sentido, necesitamos estar muy atentos en cuanto a lo que tenemos a nuestro alrededor de manera que podamos distinguir lo bueno de lo malo y así, decidir quedarnos con lo bueno y arrancar lo malo desde su raíz. Esta situación no sólo de nuestra vigilancia, sino también nuestro actuar inmediato y consecuente.

Es una cuestión de disciplina,...Cuando por la mañana uno termina de arreglarse, hay que hacer cuidadosamente la limpieza del planeta. Hay que dedicarse regularmente a arrancar los baobabs, cuando se les distingue de los rosales...A veces no hay inconveniente en dejar para más tarde el trabajo que se ha de hacer; pero cuando se trata de los baobabs, el retraso es siempre una catástrofe (De Saint Exupéry, ob. cit, p. 19).

La pereza, el desánimo, la impaciencia, la intolerancia, el odio, el desamor, entre muchas más, son los "baobabs" que debemos enfrentar día a día. Ellos inevitablemente siempre aparecerán cerca de nuestro trabajo como docentes porque 
en este mundo de complejidades todo tiene su lugar y razón de ser. Sin embargo, nuestra tarea diaria deberá ser luchar contra todos estos elementos maléficos que nos separan de los demás seres con los que compartimos el planeta. La ética compleja puede proporcionarnos de suficiente razón y pasión para logar la religación planetaria que todos necesitamos.

\section{CONCLUSIÓN}

En definitiva, la educación debería contribuir a la solidaridad en la tierra convirtiendo a la especie humana en una auténtica humanidad. La educación planteada bajo la premisa de la ética compleja o de religación, debe emerger de un ser humano responsable de la vida de todo lo que existe en la tierra. La ética compleja es en definitiva, una ética de resistencia, de amor, de reconocimiento y comprensión del otro y de sometimiento de ese espíritu egocéntrico, individualista y egoísta que todos llevamos dentro y que nos conduce al mal y a la destrucción. Por lo tanto, la ética compleja debe formar parte indispensable de nuestra labor como docentes y servir de barrera para desviar aquello que no permita lograr el fin último de la educación, que no es más que humanizar al hombre.

\section{REFERENCIAS}

Boggino, N. (2004). Los valores y las normas sociales en la escuela. Homosapiens ediciones. Santa Fe. Argentina.

De Almeida M. (2008). Para Comprender la Complejidad. Multidiversidad Mundo Real Edgar Morín, A.C., México. [Libro en Línea]. Disponible: http://www.edgarmorin.org/libros-sin-costo.html. [Consulta: 2013, Julio 15]

De Saint Exupéry, A. (2010). El Principito. Liven Editores. Caracas.

Morín, E. (2006). El Método VI. [Libro en Línea]. Disponible: www.edgarmorin.org [Consulta: 2013, Julio 05].

Morín, E.(1999). Los siete Saberes para la Educación del Futuro. [Libro en Línea]. Disponible: http://www.edgarmorin.org/libros-sin-costo.html. [Consulta: 2013, Agosto 20]

Morín, E. (1993). Tierra Patria. Nueva visión, Buenos Aires. [Libro en Línea]. Disponible: http://www.edgarmorin.org/libros-sin-costo.html. [Consulta: 2013, Julio 8] 
La ética compleja de Morín en el contexto educativo

Beatriz Teràn, Lesdy Piña ( pp.120-130)\#

Spear, W. (1997). Feng Shui. Ediciones Robinbook. Santafé Bogotá. 